\title{
Human societies began to play a significant role in global sediment transfer 4,000 years ago
}

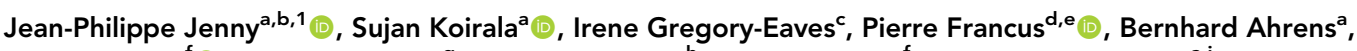 \\ Victor Brovkin ${ }^{f}\left(D\right.$, Antti E. K. Ojala ${ }^{g}$, Bernd Zolitschka ${ }^{h}$, Juergen Bader ${ }^{f}$, and Nuno Carvalhais ${ }^{a, i}$
}

In a recent study (1), we conducted a global synthesis of long-term records of reconstructed sediment accumulation rates (SARs) in lakes and diagnosed that a dominant anthropogenic imprint on soil erosion rates started $\sim 4,000$ y ago. Our approach was based on the assumption that lake SARs are watershed integrators of terrestrial biogeochemical responses to atmospheric (climate) and land surface dynamics spanning several millennia (2-4). Our statistical analysis was based on SAR reconstructions for the last 12,000 y (1), global pollen records spanning the same period to infer past vegetation changes (5), and model-based climate reconstructions from transient Holocene simulation with MPI-ESM-1.2LR developed at the Max Planck Institute for Meteorology (6), which has been previously used for analysis of coupled climate-carbon-vegetation dynamics (7).

Li et al. (8) suggest that complex "human-vegetation-climate" interactions in the Late Holocene may have biased pollen-inferred climate reconstructions. Hence, these pollen records may not be appropriate to reconstruct climate variations in addition to land cover changes. Climate can be reconstructed from pollen records (see, e.g., ref. 9), but we have chosen not to apply those data because they were already used in our study for land cover reconstruction. In fact, to avoid circularity and standardize our approach, climate time series for the past 8,000 y (i.e., average, minimum and maximum of annual precipitation, surface air temperature, and wind) were instead collected for all sites from model simulations with the MPI-ESM-
1.2LR, which does not include or assimilate the pollen records.

Li et al. (8) question the climate model selection in our study. Forcing (greenhouse gas vs. orbital) is minor; consequently, climate changes are also minor in all models. Other model reconstructions can be investigated, but, regardless of which climate reconstructions are used, the climate changes over the last 4,000 y are minor until the beginning of the 20th century. Thus, the anthropogenic factor (i.e., significant tree cover reduction synchronous to the increases in SAR trends) emerges as the dominant driver of SARs.

In our study, we show that pollen records from European and North American lakes have been affected by human activities during the Holocene, hence recording a combination of a climate and a human signal. Li et al. (8) suggest that pollen records from European and North American sites are less appropriate for climate reconstructions compared with records from remote areas. This discussion goes beyond the conclusions of our paper. The subset of sites in ref. 1 includes lake systems only, hence representing only a small fraction of all pollen archives stored in the pollen database, for example, not including bogs, ponds, swamps, soils, estuaries, or alluvial systems. Hence, our subset of pollen records is not representative of the total pollen records available, and it does not seem appropriate to discuss the climate reconstruction methodologies. Other papers discuss climate reconstruction methodologies from pollen records (9), but this was not within the scope of our paper.

\footnotetext{
aBiogeochemical Integration Department, Max Planck Institute for Biogeochemistry, 07745 Jena, Germany; ' Unite Mixte de Recherche 42, Centre Alpin de Recherche sur les Réseaux Trophiques et Ecosystèmes Limniques, Institut National de Recherche pour l'Agriculture, l'Alimentation et I'Environnement, Université Savoie Mont Blanc, 73000 Chambéry, France; 'Department of Biology, McGill University, Montréal, QC H3A 1B1, Canada; 'Centre-Eau Terre Environnement, Institut National de la Recherche Scientifique, Québec, QC G1K 9A9, Canada; ${ }^{\mathrm{e} C e n t r e ~ d e ~ R e c h e r c h e ~}$ sur la Dynamique du Systéme Terre, Université du Québec, Montréal, QC H3C 3P8, Canada; 'Land in the Climate System Department, Max Planck Institute for Meteorology, 20146 Hamburg, Germany; ${ }^{9}$ Geological Survey of Finland, 02151 Espoo, Finland: heomorphology and Polar Research, Institute of Geography, University of Bremen, D-28359 Bremen, Germany; and 'Departamento de Ciências e Engenharia do Ambiente, Faculdade de Ciências e Tecnologia, Universidade Nova de Lisboa, 2829-516 Caparica, Portugal

Author contributions: J.-P.J. and S.K. designed research; and J.-P.J., S.K., I.G.-E., P.F., B.A., V.B., A.E.K.O., B.Z., J.B., and N.C. wrote the paper.

The authors declare no competing interest.

Published under the PNAS license.

${ }^{1}$ To whom correspondence may be addressed. Email: Jean-Philippe.Jenny@inrae.fr.
} 
1 J.-P. Jenny et al., Human and climate global-scale imprint on sediment transfer during the Holocene. Proc. Natl. Acad. Sci. U.S.A. 116, 22972-22976 (2019).

2 K. J. Edwards, G. Whittington, Lake sediments, erosion and landscape change during the Holocene in Britain and Ireland. Catena 42, 143-173 (2001).

3 J. A. Dearing, Lake sediment records of erosional processes. Hydrobiologia 214, 99-106 (1991).

4 C. E. Williamson, J. E. Saros, W. F. Vincent, J. P. Smol, Lakes and reservoirs as sentinels, integrators, and regulators of climate change. Limnol. Oceanogr. 54, 22732282 (2009).

5 A. C. Martin, W. J. Harvey, The Global Pollen Project: A new tool for pollen identification and the dissemination of physical reference collections. Methods Ecol. Evol. 8, 892-897 (2017)

6 T. Mauritsen et al., Developments in the MPI-M Earth System Model version 1.2 (MPI-ESM1.2) and its response to increasing CO 2. J. Adv. Model. Earth Syst. 11, 998-1038 (2019).

$7 \mathrm{~V}$. Brovkin et al., What was the source of the atmospheric $\mathrm{CO}_{2}$ increase during the Holocene? Biogeosciences 16, 2543-2555 (2019).

8 Y. Li et al., Complex "human-vegetation-climate" interactions in the Late Holocene and their significance for paleotemperature reconstructions. Proc. Natl. Acad. Sci. U.S.A., 10.1073/pnas.1922325117 (2020).

9 B. A. S. Davis, S. Brewer, A. C. Stevenson, J. Guiot, The temperature of Europe during the Holocene reconstructed from pollen data. Quat. Sci. Rev. 22, 17011716 (2003) 